\title{
Analisis dan Perencanaan Pengembangan Sistem Distribusi Air Minum di PDAM Unit Plosowahyu Kabupaten Lamongan
}

\author{
Ricki Novan Armanto dan Hariwiko Indarjanto \\ Jurusan Teknik Lingkungan, Fakultas Teknik Sipil dan Perencanaan, Institut Teknologi Sepuluh Nopember (ITS) \\ Jl. Arief Rahman Hakim, Surabaya 60111 Indonesia \\ e-mail: hwcorp@yahoo.com
}

\begin{abstract}
Abstrak-PDAM Kabupaten Lamongan memiliki 2 lokasi IPAM, yaitu IPA Babat dan IPA Plosowahyu. Di IPA Plosowahyu direncanakan akan ditingkatkan kapasitasnya sebesar 100 lt/detik, dari awalnya sudah 100 lt/detik. Kondisi di lapangan di tahun 2016, belum terealisasi kapasitas produksi 200 It/detik tersebut. Diketahuinya rencana pengembangan tersebut, maka akan dianalisis sistem yang sudah ada dahulu dan kemudian dianalisis perencanaan pengembangannya. Aplikasi yang digunakan untuk menganalisis kondisi eksisting dan pengembangan nantinya adalah aplikasi Epanet 2.0. Hasil analisis kondisi menunjukkan running tidak sukses. Perencanaan dilakukan dalam 2 tahap, yaitu tahun (2021-2021) dan tahun (2012-2026). Wilayah pengembangan yang ditargetkan mulai tahun 2021 ini adalah Kelurahan Made yang awalnya telah dilayani IPA Unit Babat, oleh karena dibentuknya blok atau zona sebanyak 37 blok. Tujuan dibentuknya blok ini, untuk memudahkan kontrol sistem ditribusi. Perbaikan pipa yang dilakukakan ini juga dibagi menjadi tahap, yaitu di tahun 2021 dan tahun 2026. Hal ini untuk menekan biaya perencanaan, karena anggaran pembangunan yang digunakan juga akan dibagi menjadi 2 tahap.
\end{abstract}

Kata Kunci- Epanet 2.0, pengembangan, sistem distribusi, Unit Plosowahyu, zona

\section{PENDAHULUAN}

S ALAH satu tugas pemerintah yang tertuang dalam standar pelayanan minimum adalah dapat memenuhi kebutuhan dasar masyarakat, yang tercakup didalamnya menyediakan pelayanan minimal air bersih masyarakat [1]. Pelayanan air bersih kepada masyarakat, sistem jaringan distribusi dari suatu kesatuan sistem penyediaan air bersih merupakan bagian yang sangat penting. Fungsi pokok dari jaringan pipa distribusi adalah untuk mengalirkan air bersih keseluruh pelanggan dengan tetap memperhatikan faktor kualitas, kuantitas dan kontinuitas, serta tekanan air. Sistem distribusi air minum sangat dimungkinkan terjadi perubahan kualitas air terutama dari sisi biologi. Penjaminan kualitas air minum dari sisi biologi (dinyatakan bebas bakteri) dipenuhi dengan konsentrasi khlor minimal sebesar $0,2 \mathrm{mg} / \mathrm{l}$, dengan batas maksimum konsentrasi pembubuhan pada tandon sebesar 1 $\mathrm{mg} / \mathrm{l}[2]$.

Di Kabupaten Lamongan ini terdapat 2 lokasi Water Treatement, yaitu Unit Plosowahyu dan Unit Babat. Dan yang dikaji ini nantinya adalah unit yang ada di PDAM unit Plosowahyu. Sesuai dengan rencana yang telah dituangkan dalam Corporate Plan PDAM, bahwa IPA Plosowahyu akan ditingkatkan menjadi 200 Lt/detik pada tahun 2015 [3]. Diketahuinya berbagai masalah yang ada pada jaringan distibusi yang sudah ada, maka dapat diberikan solusi dengan penyaluran tingkat pelayanan debit yang diambil dari instalasi baru tersebut. Disini juga akan dievaluasi berbagai kekurangan dan penyelesaiannya. Memang tingkat pelayanan debit dan tekanan sudah baik, dan ternyata debit dari instalasi baru tersebut masih tersisa besar, maka dalam jangka waktu kedepan dapat direncanakan pengembangan jaringan distribusi di Kabupaten Lamongan, terutama dari instalasi PDAM Plosowahyu.

\section{METODE PERENCANAAN}

\section{A. Perijinan}

Proses perijinan dilakukan dengan pembuatan proposal dan surat pengantar dari Jurusan Teknik Lingkungan ITS, yang ditujukan kepada Kepala Bakesbangpol Kabupaten Lamongan. Dari Bakesbangpol ini, maka berikutnya akan ada surat tembusan yang ditujukan ke instansi PDAM Kabupaten Lamongan, BAPPEDA, dan BPS Kabupaten Lamongan. Proses perijinan jika telah dilakukan sesuai regulasi yang ada, maka bisa dilakukan proses pengambilan data dari ketiga instansi tersebut.

\section{B. Pengumpulan Data Priner}

1) Observasi dan pengamatan kondisi lapangan, dilakukan dengan tujuan melihat kondisi wilayah perencanaan yang akan dilakukan. Observasi ini meliputi, kondisi jalan, pola atau kondisi pemukiman, jaringan pipa eksisting, dan juga elevasi kondisi wilayah perencanaan yang bisa memakai alat bantu GPS (Global Positioning System).

2) Data kebutuhan air, akan dilakukan langsung pada lapangan. Tujuannya untuk menentukan besarnya kebutuhan air per orang per harinya. Cara untuk menentukannya, dilakukan pengecekan pada beberapa SR yang dapat digunakan sebagai wakilnya. Penentuan SR yang akan disurvei ini, haruslah SR yang memang terlayani air PDAM secara 24 jam.

3) Analisis BPC ini bertujuan untuk menganalisis apakah proses desinfeksi yang ada di IPA Plosowahyu sudah efektif atau belum. Sampel air yang diambil adalah air yang sebelum menuju ke reservoir. 


\section{Pengumpulan Data Sekunder}

1) Peta RTRW Kabupaten Lamongan untuk menentukan arah daerah yang akan dikembangkan.

2) Data eksisting PDAM unit Plosowahyu Kabupaten Lamongan, yang meliputi persentase pelayanan, pipa jaringan distribusi, dan kebocoran dalam jaringan.

3) Data jumlah penduduk Kabupaten Lamongan, khususnya di Kecamatan Lamongan, Kecamatan Tikung dan Kecamatan Deket.

4) Data teknis PDAM unit Plosowahyu Kabupaten Lamongan, diantaranya tekanan air dan jaringan distribusi

D. Pengolahan Data

i) Proyeksi penduduk dilakukan untuk memperkirakan jumlah penduduk yang akan dilayani pada masa yang akan dating. Proyeksi ini dilakukan untuk 10 tahun yang akan dating. Ketiga metode tersebut, nantinya hanya akan dipilih satu metode yang benar-benar sesuai.

ii) Kebutuhan air untuk sistem distribusi ini, dengan menggunakan debit jam puncak. Kebutuhan air yang diperhitungkan adalah kebutuhan air domestik, non domestik dan estimasi kebocoran. Kebutuhan air domestik didapatkan dari proyeksi penduduk. Kebutuhan air non domestik didapatkan dari proyeksi fasilitas umum. Tingkat kebocoran air dapat dihitung berdasarkan jumlah air yang diproduksi oleh PDAM unit Plosowahyu dan air yang terjual ke pelanggan atau dengan bantuan data PDAM yang telah ada.

iii) Faktor jam puncak, ditentukan dengan melihat kondisi realita di lapangan. Cara lain yang bisa digunakan adalah dengan berdasarkan faktor skala $(1,5-1,75)$.

iv) Keadaan eksisiting ditingkat pelanggan, dapat diketahui dari hasil running menggunakan software Epanet 2.0. Sistem distribusi yang ditinjau adalah jaringan pipa yang tidak memenuhi kriteria seharusnya (Pedoman/Petunjuk Teknik dan Manual KIMPRASWIL tahun 2002) dan akan dilakukan evaluasi.

\section{E. Pemodelan Kondisi Eeksisting dengan Software Epanet} 2.0

Data-data yang telah lengkap, kemudian diaplikasikan dengan menggunakan software Epanet 2.0 untuk melakukan pengolahan data. Data-data yang dimasukkan ke dalam program Epanet 2.0 adalah primer (seperti elevasi) dan data sekunder (seperti panjang pipa, diameter pipa, kekasaran pipa, demand, head dan debit pompa, dan lain-lain). Perencanaan pengembangan sistem distribusi

Pengembangan sistem distribusi ini dilakukan berdasarkan beberapa pertimbangan yang bisa meliputi, tata guna lahan, rencana tata ruang Kabupaten Lamongan, dan pengamatan kondisi lapangan yang ada.

Dipengembangan ini, ditentukan daerah mana yang akan dikembangkan. Pengembangan juga dilakukukan sebanyak 2 tahap, yaitu di tahun 2016-2021 dan tahun 2022-2026. Running Epanet 2.0 juga harus dilakukan sebanyak dua kali, yaitu di tahun 2021 dan tahun 2026.

\section{HASIL DAN PEMBAHASAN}

\section{A. Analisis Kondisi Eksisting}

Pada analisa kondisi eksisting ini, bertujuan untuk menganalisa antara data eksisting yang dimiliki oleh PDAM, dengan analisa perhitungan yang akan dilakukan. Analisa yang dilakukan, meliputi tingkat pelayanan,kebutuhan air rata-rata, perhitungan kebutuhan air, dan analisis dengan aplikasi Epanet 2.0.

1) Tingkat Pelayanan

Wilayah pelayanan yang yang sudah terlayani, terdapat 14 kelurahan dari 3 kecamatan, diantaranya adalah 9 kelurahan di Kecamatan Lamongan, 3 kelurahan di Kecamatan Deket, dan 1 kelurahan di Kecamatan Tikung. Kelurahan yang telah terlayani ini, berdasarkan data terbaru hingga awal tahun 2016. Wilayah pelayanan oleh IPA Plosowahyu, dapat dilihat pada Tabel 1.

Tabel 1.

Wilayah Kelurahan yang Terlayani IPA Plosowahyu

\begin{tabular}{cccl}
\hline \hline No & $\begin{array}{c}\text { No } \\
\text { Kelurahan }\end{array}$ & Kecamatan & \multicolumn{1}{c}{ Kelurahan } \\
\hline 1 & 1 & & Sidomukti \\
2 & 2 & & Tlogoanyar \\
3 & 3 & & Sidoharjo \\
4 & 4 & Lamongan & Sukomulyo \\
5 & 5 & & Sukorejo \\
6 & 6 & & Jetis \\
7 & 7 & & Banjarmendalan \\
8 & 8 & & Sidokumpul \\
9 & 9 & & Deket Kulon \\
10 & 1 & Deket & Deket Wetan \\
11 & 2 & & Sidorejo \\
12 & 3 & Tikung & Tambakrigadung \\
13 & 1 & & \\
\hline \hline
\end{tabular}

2) Tingkat Kebutuhan Air

Penentuan tingkat kebutuhan air, dibagi menjadi 2, yaitu kebutuhan air domestik dan kebutuhan air non domestik. Hasil survei yang telah dilakukan, maka kebutuhan air per orang per hari adalah 122,2 lt/orang.hari.

Untuk kebutuhan air non domestik, dengan memakai data sekunder berdasarkan dari PDAM, yang dipilih berdasarkan yang mayoritas dan kebutuhan air pada umumnya. Kategori non domestik yang dipilih antara lain sosial, niaga, industri kecil, dan industri besar. Debit eksisting yang terhitung hanya sebesar 63,574 Lt/detik, jadi jika dihitung besarnya kehilangan air adalah sebesar $37 \%$.

3) Analisis Sistem Distribusi Kebutuhan Air Eksisting Sistem distribusi yang terlayani oleh IPA Plosowahyu, menggunakan sistem pemompaan. Hal ini disebabkan oleh datarnya elevasi tanah yang ada di Kabupaten Lamongan. Di pelayanan distribusi IPA Plosowahyu ini sendiri, memanfaatkan 2 ground reservoir di bagian tengah-tengah sistem distribusinya, yang berfungsi sebagai pengatur tekanan agar tetap stabil.

Perhitungan kebutuhan air eksisting ini, perlu dilakukan beberapa tahapan agar memudahkan dalam analisa kebutuhan air eksisting, yaitu:

a) Menentukan jaringan pipa induk distribusi 
b) Membuat blok pelayanan

Pembangian blok yang telah dilakukan, maka terdapat 29 blok untuk kondisi eksiting ini.

c) Perhitungan debit blok

Perhitungan debit ini, dilakukan berdasarkan pembagian persentase jalan yang sudah terlayani dengan mengacu pada data PDAM.

4) Analisis Eksisting Menggunakan Epanet 2.0

Data-data yang perlu dimasukkan untuk membantu pemodelan ini, diantaranya adalah elevasi, panjang pipa, diameter pipa, debit blok/zona, kekasaran pipa, data reservoir berupa elevasi, data pompa berupa head dan debit pompa. Dalam pemompaan sistem distribusi kali ini, tidak memakai input data fluktuasi pemompaan yang dimasukkan pada menu Pattern di aplikasi Epanet 2.0. Cara lain untuk mengatasi ini, yaitu hanya dengan memasukkan faktor jam puncak pada Demand Multiplier (Option - Hydraulic Option - Demand Multiplier). Rentang nilai yang bisa dipilih adalah $(1,5-1,75)$, namun angka yang dipilih kali ini adalah 1,75 .

Hasil running yang akan ditampilkan ini adalah hasil dari node dan pipa. Node pada running ini menunjukkan hasil dari pressure, base demand, demand, dan head. Pressure adalah sisa tekan setelah melewati beberapa friksi, baik yang disebabkan oleh kekasaran pipa maupun panjang pipa. Base demand adalah kebutuhan air atau debit yang diinput pada tiap blok. Demand adalah kebutuhan air atau debit pada saat jam puncak, yang didapat dengan cara base demand dikalikan dengan faktor pengali jam puncak dan nilai tersebut adalah 1,75 .

Hasil running untuk pipa, nantinya akan menghasilkan flow, velocity, dan unit headloss. Berikut adalah hasil running eksisting, yang ditunjukkan pada gambar 1 .
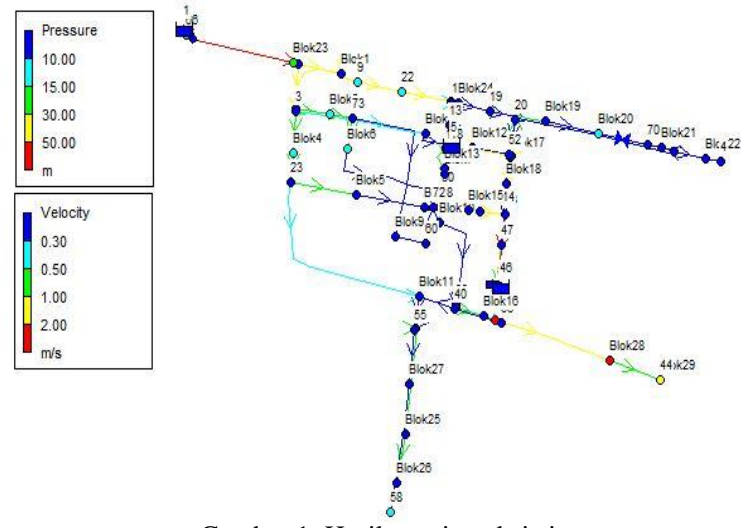

Gambar 1. Hasil running eksisting

Pada running tersebut telah menunjukkan pemberitahuan bahwa running tidak sukses, yang artinya dalam sistem pemodelan tidak berhasil dan kemungkinan terdapat beberapa masalah dalam sistem distribusi eksisting.

Pada kriteria perencanaan, tekanan atau pressure yang baik, minimal adalah $10 \mathrm{~m}$ dan maksimal $80 \mathrm{~m}$. Analisis yang menyebabkan terjadi negatif, juga karena headloss yang terlalu besar. Semakin besarnya kehilangan tekanan/ headloss, maka sisa tekan (pressure) juga akan semakin kecil. Solusi untuk mengatasi masalah terseut, maka nantinya bisa dilakukan penggantian pipa pada jalur tersebut atau bisa dengan mempararel pipa.

Sistem distribusi yang ada hingga tahun 2016 ini, mamanfaatkan 3 sistem pemompaan yang bertujuan untuk tetap menjaga pelayanan agar tetap baik. Pemompaan tersebut, diantaranya pertama ada di IPA Plosowahyu sendiri, dan kedua pemompaan sisanya ada di tengah-tengah sistem distribusi yang memanfaatkan ground reservoir. Data pemompaan yang terjadi hingga tahun 2016 ini, akan ditunjukkan pada tabel 2 .

Tabel 2.

Data pemompaan di tahun 2016

\begin{tabular}{clcc}
\hline \hline $\begin{array}{c}\text { No Node } \\
\text { ID }\end{array}$ & \multicolumn{1}{c}{ Lokasi } & $\begin{array}{c}\text { Debit } \\
\text { (L/detik) }\end{array}$ & Head (m) \\
\hline Pump 1 & IPAM & 100 & 45 \\
Pump 72 & Kantor PDAM & 60 & 25 \\
Pump 69 & J1. Veteran & 30 & 50 \\
\hline \hline
\end{tabular}

\section{B. Proyeksi Penduduk dan Fasilitas Umum}

1) Proyeksi Penduduk

Perhitungan proyeksi penduduk memiliki tiga metode yang dapat digunakan, yaitu metode aritmatik, geometrik, dan metode least square. Dari ketiga metode tersebut terpilih menggunakan metode geometrik, dengan rumus perhitungan pertumbuhan penduduk sebagai berikut :

$$
\mathrm{Pn}=\mathrm{Po}(1+\mathrm{r})^{\mathrm{n}}
$$

Dimana :

Pn = Jumlah penduduk pada akhir tahun periode

Po $=$ Jumlah penduduk pada awal proyeksi

$\mathrm{r}$ = rata-rata persentase pertambahan penduduk tiap tahun.

$\mathrm{n}$ = kurun waktu.

Dalam menghitung nilai korelasi digunakan rumus sebagai berikut :

$$
\mathrm{r}=\frac{\mathrm{n}\left(\sum x Y\right)\left(\sum y\right)}{\left.\sqrt{\left[n\left(\sum y^{2}\right)-\left(\sum Y\right)^{2}\right.}\right] \sqrt{\left[n\left(\sum x^{2}\right)-(\Sigma x)^{2}\right]}}
$$

$$
\begin{aligned}
& \text { Keterangan: } \\
& \mathrm{r} \quad=\text { koefisien korelasi } \\
& \mathrm{X}=\text { nomor data } \\
& \mathrm{Y}=\text { data penduduk per tahun } \\
& \mathrm{n} \quad=\text { jumlah data }
\end{aligned}
$$

\section{2) Proyeksi Fasilitas Umum}

Persamaan yang digunakan untuk menghitung proyeksi fasilitas umum, yaitu:

$$
\mathrm{Fn}=\mathrm{w} \times \mathrm{Fo}
$$

Keterangan:

Fn $\quad=$ Jumlah fasilitas untuk tahun ke-n

$\mathrm{W}=$ Perbandingan jumlah penduduk pada tahun ke$\mathrm{n}$ dengan jumlah penduduk pada tahun ke- 0

\section{Proyeksi Kebutuhan Air}


1) Persentase Pelayanan

Perhitungan kebutuhan air ini, sebelumnya perlu dilakukan perhitungan persentase pelayanan eksisting di tiap kelurahannya. Tujuan dari persentase ini, untuk mengetahui kondisi persentase pelayanan eksisiting ditahun 2016 dan kemudian nantinya bisa dilakukan proyeksi peningkatan persentase pelayanan di tiap tahunnya. Berikut persentase pelayanan eksisting tahun 2016, yang ditunjukkan pada tabel 3.

Tabel 3.

Persentase pelayanan di tahun 2016

\begin{tabular}{cclc}
\hline \hline No & Kecamatan & \multicolumn{1}{c}{ Kelurahan } & $\begin{array}{c}\% \\
\text { Pelayanan }\end{array}$ \\
\hline 1 & & Sidomukti & 45 \\
2 & & Tlogoanyar & 99,4 \\
3 & \multirow{2}{*}{ Lamongan } & Sidoharjo & 99,2 \\
4 & & Sukomulyo & 37,4 \\
5 & & Sukorejo & 78,6 \\
6 & & Tumenggungan & 60,9 \\
7 & & Jetis & 100 \\
8 & & Banjarmendalan & 88 \\
9 & & Sidokumpul & 61 \\
10 & & Deket Kulon & 40 \\
11 & \multirow{2}{*}{ Deket } & Deket Wetan & 17 \\
12 & & Sidorejo & 49 \\
13 & Tikung & Tambakrigadung & 52 \\
\hline \hline
\end{tabular}

2) Proyeksi Kebutuhan Air dan Pengembangan

Perencanaan pengembangan ini dibagi menjadi 2 tahap, yaitu tahap 1 (2016-2021) dan tahap 2 (2022-2026). Wilayah utama yang diproyeksikan mengalami peningkatan pelayanan, misalnya adanya perumahan baru. Wilayah baru yang berpotensi dilayani oleh sistem distribusi IPA Plosowahyu, adalah Kelurahan Made. Saat ini Kelurahan Made sendiri telah dilayani oleh IPA Babat atau mengikuti sistem distribusi yang lama. Beberapa hal yang dicantumkan dalam proyeksi kebutuhan air ini adalah:

a) Persentase pelayanan

b) Jumlah penduduk terlayani

c) Sambungan rumah (SR)

d) Fasilitas pendidikan

e) Fasilitas kesehatan

f) Fasilitas tempat ibadah

g) Fasilitas industri besar

h) Fasilitas industri kecil

i) Fasilitas penginapan

j) Kebutuhan air total domestik dan non domestic

k) Besarnya kehilangan air

1) Total kebutuhan air setelah kebocoran

m) Total kebutuhan air saat jam puncak

n) Total kebutuhan air saat hari maksimum

Kebutuhan air di tahun 2016 sendiri, hasil perhitungan sudah hampir sesuai dengan data kebocoran yang ada, yaitu sebesar 30\% dari $100 \mathrm{Lt} /$ detik. Berdasarkan perhitungan kebutuhan air jam puncak, menunjukkan bahwa kebutuhan air pada tahun 2021 sudah terlalu besar. Oleh karena itu, pada tahun tersebut harus sudah ada penambahan produksi air sehingga pelanggan tetap terlayani oleh air minum
PDAM, minimal $100 \mathrm{Lt} /$ detik lagi. Hal ini supaya bisa mencukupi hingga tahun 2026,

3) Skematik Sistem Distribusi

Skematik sistem distribusi ini akan menunjukkan perbandingan sistem distribusi yang eksisting di tahun 2016 dengan sistem distribusi saat sudah mulai dilakukan pengembangan. Melihat skematik sistem distribusi yang sudah mulai dikembangkan pada tahun 2021, ground reservoir yang ada di kantor PDAM, nantinya juga akan melayani wilayah Deket. Air yang di Jl. Veteran juga akan didistribusikan hampir secara menyeluruh dan saling terhubung. Berikut perbedaan skematik, yang ditunjukkan pada gambar 2 dan gambar 3.

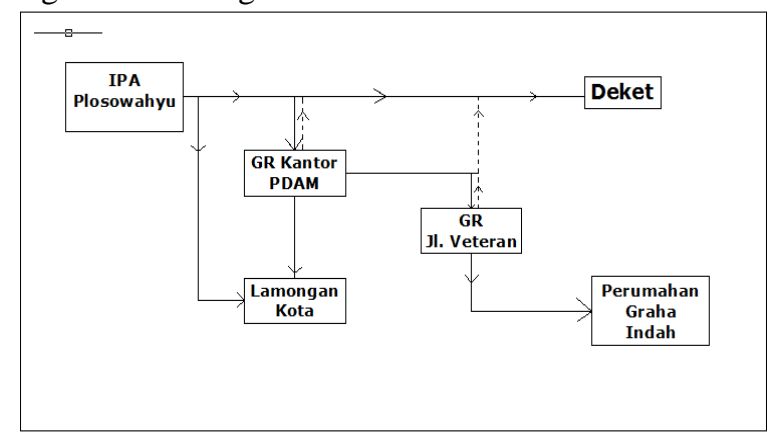

Gambar 2. Skematik pelayanan eksisting tahun 2016

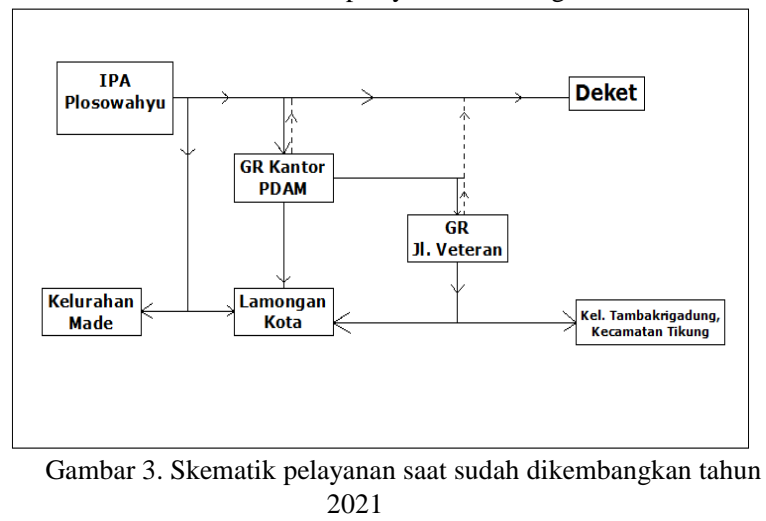

D. Analisis Epanet 2.0 Wilayah Pengembangan

Diketahuinya hasil proyeksi dari kebutuhan air hingga tahun 2026, maka dapat dilakukan pemodelan sistem distribusi dengan menggunakan Epanet 2.0. Tujuan dari pemodelan ini, untuk melihat kondisi sistem distribusi, apakah akan menjadi lebih baik atau bahkan lebih buruk dari sistem eksisting di tahun 2016. Proses pemodelan ini, akan dilakukan sebanyak 2 kali, yaitu di tahun 2021 dan tahun 2026 sesuai analisis sebelumnya.

1) Analisis Kebutuhan Air Tiap Blok

Analisis kebutuhan air untuk daerah pengembangan ini, akan dilakukan sebanya 2 tahap. Perhitungan kebutuhan air tiap bloknya pun juga akan dilakukan sebanyak 2 tahap, sehingga proses pemodelan yang akan dilakukan di Epanet 2.0 juga dilakukan sebanyak dua kali. Jumlah blok di tahun (2017-2021) ini, juga mengalami peningkatan dari jumlah blok yang telah dibuat di eksisting dan ini akan bertahan hingga tahun (2022-2026). Total blok mulai tahun 2021 ini adalah sebanyak 37 blok. 
2) Analisis Epanet 2.0

Analisis epanet pada wilayah pengembangan ini, merupakan hasil pemodelan kondisi sistem distribusi pada tahun 2021 dan tahun 2026. Pemodelan akan dilakukan terhadap tahap pertama dahulu, yaitu pada tahun 2021.

Hasil setelah running Epanet 2.0 di tahun 2026 telah menunjukkan sukses. Suksesnya running ini, menunjukkan bahwa sistem telah berjalan dengan baik, Solusi yang dilakukan untuk mengatasi masalah dianalisis eksisting, yaitu dengan melakukan pararel pipa agar tidak terjadi negative pressure. Tujuan dari pararel pipa adalah untuk membagi tekanan dan mengurangi unit headloss. Diketahui bahwa semakin besar unit headloss dan pipa juga terlalu panjang, maka friction/ kehilangan tekanan juga akan semakin besar..

Lokasi-lokasi yang terpaksa dilakukan pararel pipa pada tahun 2021 ini, diantaranya adalah pipe 72 yang sebesar $150 \mathrm{~mm}$ dan pipe 69 yang sebesar $200 \mathrm{~mm}$ yang ada di $\mathrm{Jl}$. Veteran. Di sepanjang jalan yang akan menuju ke Kelurahan Tambakrigadung juga harus dilakukan pemararelan pipa, diantaranya pipa $250 \mathrm{~mm}$ yang sepanjang $602 \mathrm{~m}$, dan pipa $200 \mathrm{~mm}$ yang sepanjang 1241 $\mathrm{m}$. Lokasi lainnya yang perlu dilakukan pemararelan pipa adalah di Jl. Lamongrejo sebelum air dimasukkan ke dalam ground reservoir yang ada di Kantor PDAM. Besarnya pipa yang dipararelkan adalah pipa $250 \mathrm{~mm}$ yang sepanjang $400 \mathrm{~m}$. Lokasi berikutnya yang harus dilakukan pararel pipa adalah di sepanjang jalan yang akan menuju Kelurahan Made, yaitu harus dipararel pipa dengan diameter $150 \mathrm{~mm}$ yang sepanjang $200 \mathrm{~m}$. Pipa yang ada di $\mathrm{Jl}$. Merpati juga perlu dilakukan pararel, yaitu dengan pipa berdiameter $150 \mathrm{~m}$ sepanjang $627 \mathrm{~m}$. Lokasi terakhir yang perlu dilakukan parare pipa di tahun 2021 adalah di Jl. Kombespol M. Duryat, yaitu pipa sebesar $150 \mathrm{~mm}$ yang sepanjang $533 \mathrm{~m}$. Hasil running tersebut, memanfaatkan sistem pemompaan dan pada tahun 2021 ini, tidak harus mengganti sistem pemompaan dari eksistingnya di tahun 2016. Sistem pemompaan, harus dilakukan pararel untuk di IPA Plosowahyu dan kantor PDAM, sedangkan sistem pemompaan di Jl. Veteran, tetap dalam keadaan semula. Berikut data dan sistem pemompaan yang dipakai mulai tahun 2021, yang ditunjukkan pada tabel 4 .

Tabel 4.

Kapasitas pompa di tahun 2021

\begin{tabular}{|c|c|c|c|c|}
\hline $\begin{array}{l}\text { Lokasi } \\
\text { Pompa }\end{array}$ & $\begin{array}{c}\text { Flow } \\
\text { (Lt/detik) }\end{array}$ & $\begin{array}{c}\text { Head } \\
(\mathbf{m})\end{array}$ & Sistem & $\begin{array}{l}\text { Jumlah } \\
\text { Pompa }\end{array}$ \\
\hline IPA & & & & \\
\hline $\begin{array}{l}\text { Plosowahyu } \\
\text { Kantor }\end{array}$ & 121 & 70 & Pararel & 2 \\
\hline PDAM & 100 & 50 & Pararel & 3 \\
\hline Jl. Veteran & 30 & 50 & Single & 1 \\
\hline
\end{tabular}

Pemodelan untuk tahap kedua, yaitu pada tahun 2026 bertujuan untuk melihat sistem distribusi pada tahun 2026 . Sistem di tahun 2026 ini, sebagian besar tidak ada bedanya dengan sistem distribusi ditahun 2021. Perbedaan pada tahun 2026 ini hanya pada peningkatan debit pelayanan.

Lokasi-lokasi yang perlu dilakukan pararel pipa di tahun 2026 ini, diantaranya adalah di Jl. J. A. Suprapto yang merupakan pipa utama dari distribusi dari IPA Plsowahyu menuju ke sistem distribusi. Pipa tersebut perlu dilakukan pararel pipa sepanjang $500 \mathrm{~m}$ dengan diameter $250 \mathrm{~mm}$. Kode pipa tersebut jika di Epanet adalah Pipe 106. Lokasi lain yang perlu dilakukan pararel pipa lainnya adalah di Jl. Pahlawan dengan kode pipa di Epanet adalah Pipa 100. Besarnya pipa ini adalah $150 \mathrm{~mm}$ dengan panjang $336 \mathrm{~m}$. Berikut adalah hasil running epanet yang ditunjukkan pada tahun 2021 dan tahun 2026, yang ditunjukkan pada gambar 4 dan gambar 5 .

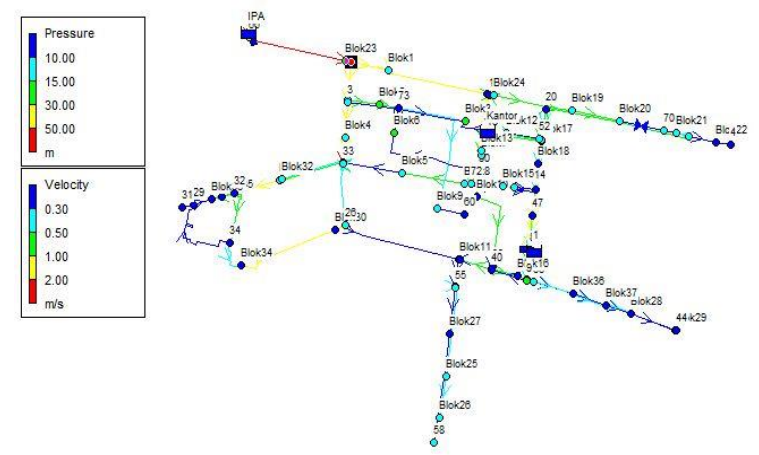

Gambar 4. Pemodelan pengembangan di tahun 2021

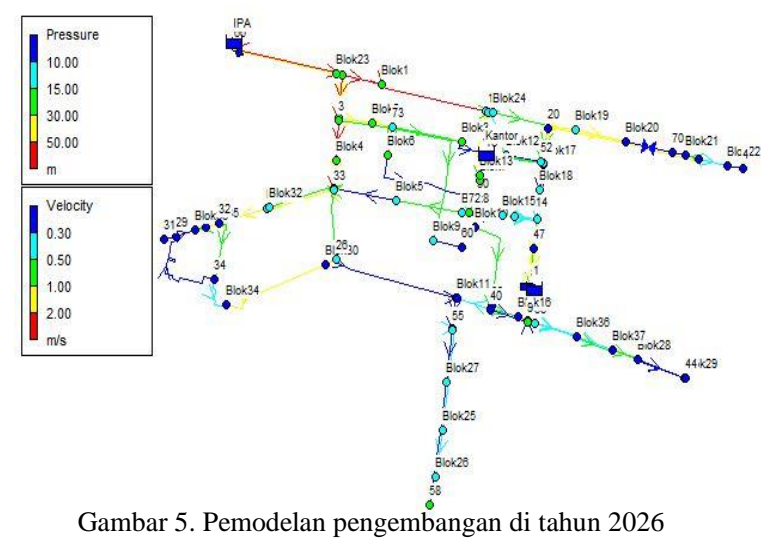

E. Analisis Desinfeksi

Analisa desinfeksi ini, bertujuan untuk menganalisis bahwa apakah pengolahan desinfeksi yang ada di IPA Plosowahyu tersebut sudah benar atau belum.

1) Analisa Laboratorium

Berdasarkan data hasil laboratorium dan grafik, maka didapat konsentrasi kaporit optimum, sebesar 0,603 mg/lt dengan sisa khlor $0,28 \mathrm{mg} / \mathrm{lt}$.

2) Analisa Kebutuhan Gas Khlor

Berdasarkan perhitungan dan konversi yang telah dilakukan, maka pembubuhan injeksi gas khlor yang telah ada di IPA Plosowahyu sudah dalam keadaan benar. Hal ini karena injeksi gas khlor di lapangan adalah sebesar $0,5 \mathrm{~kg} / \mathrm{jam}$, sedang berdasarkan perhitungan adalah $0,19 \mathrm{~kg} / \mathrm{jam}$.

\section{F. BOQ dan RAB Perencanaan}

Perencanaan dilakukan sebanyak 2 tahap, maka perhitungan BOQ dan RAB ini juga akan dilakukan sebanyak 2 tahap, yaitu di tahun (2017-2021) dan tahun (2022-2026). Lokasi perencanaan pengembangan tersebut, akan ditunjukkan pada Tabel 5 dan Tabel 6. 
Tabel 5.

Lokasi perencanaan pembangunan baru di tahap pertama

\begin{tabular}{|c|c|c|}
\hline No. & Lokasi & Kode Epanet \\
\hline \multirow{3}{*}{1} & \multirow{3}{*}{ Jl. Mastrip } & Pipe 87 \\
\hline & & Pipe 6 \\
\hline & & Pipe 56 \\
\hline \multirow[t]{2}{*}{2} & \multirow[t]{2}{*}{ Perkampungan Made } & Pipe 65 \\
\hline & & Pipe 88 \\
\hline \multirow{3}{*}{3} & \multirow{3}{*}{ Jalan Baru } & Pipe 74 \\
\hline & & Pipe 77 \\
\hline & & Pipe 72 \\
\hline \multirow[t]{2}{*}{4} & \multirow[t]{2}{*}{ J1. Veteran } & Pipe 69 \\
\hline & & Pipe 1 \\
\hline 5 & Jalan Merpati & Pipe 98 \\
\hline \multirow{3}{*}{6} & \multirow{3}{*}{ Kombespol M. Duryat } & Pipe 99 \\
\hline & & Pipe 100 \\
\hline & & Pipe 94 \\
\hline \multirow{3}{*}{7} & \multirow{3}{*}{ Arah ke Perum. Graha indah } & Pipe 102 \\
\hline & & Pipe 103 \\
\hline & & Pipe 104 \\
\hline
\end{tabular}

Tabel 6.

Lokasi perencanaan pembangunan baru di tahap kedua

\begin{tabular}{clc}
\hline \hline No. & \multicolumn{1}{c}{ Lokasi } & Kode Epanet \\
\hline 1 & Jl. J.A. Suprapto & Pipe 106 \\
2 & Jl. Pahlawan & Pipe 100 \\
\hline \hline
\end{tabular}

Berikut adalah rincian biaya yang dibutuhkan selama perencanaan dan ini juga sudah dibagi dalam tiap tahapnya, yaitu ditunjukkan pada tabel 7 dan tabel 8 .

Tabel 7.

Total biaya pada tahun 2021

\begin{tabular}{clcc}
\hline \hline No & \multicolumn{1}{c}{ Jenis RAB } & Biaya \\
\hline 1 & Biaya Pekerjaan & $\mathrm{Rp}$ & $703.061 .425,13$ \\
2 & Pipa dan Aksesoris Pipa & $\mathrm{Rp}$ & $719.396 .905,00$ \\
3 & Thrust Block & $\mathrm{Rp}$ & $2.369 .981,20$ \\
4 & Detail Jucntion Blok & $\mathrm{Rp}$ & $759.914 .796,30$ \\
& $\quad$ Total RAB & $\mathrm{Rp}$ & $\mathbf{2 . 1 8 4 . 7 4 3 . 1 0 7 , 6 3}$ \\
\hline \hline
\end{tabular}

Tabel 7.

Total biaya pada tahun 2026

\begin{tabular}{clcc}
\hline \hline No & \multicolumn{1}{c}{ Jenis RAB } & & Biaya \\
\hline 1 & Biaya Pekerjaan & $\mathrm{Rp}$ & $156.225 .918,52$ \\
2 & Pipa dan Aksesoris Pipa & $\mathrm{Rp}$ & $217.361 .245,00$ \\
3 & Thrust Block & $\mathrm{Rp}$ & $1.029 .264,95$ \\
& Total RAB & Rp & $\mathbf{3 7 4 . 6 1 6 . 4 2 8 , 4 6}$ \\
\hline \hline
\end{tabular}

\section{KESIMPULAN}

a. Pada masing-masing kelurahan yang telah terlayani oleh sistem distribusi IPA Plosowahyu, dilakukan peningkatan persentase pelayanan untuk Kecamatan Lamongan, Kecamatan Deket, dan Kecamatan Tikung yang telah terlayani sampai tahun 2016 saat ini. Rata-rata peningkatan persentase pelayanan ini adalah $10 \%$ untuk wilayah yang sudah cukup banyk dalam pelayanan.

b. Dibentukknya sistem zona atau blok pada tiap kawasan dan totalnya terbentuk hingga 37 blok, untuk memantau dan membagi perataan pelayanan dengan mengatur debit air yang diberikan kepada tiap kawasan tersebut.

c. Dilakukannya analisis injeksi gas khlor, yaitu dengan cara melakukan percobaan untuk menentukan pembubuhan kaporit yang optimum. Nilai konsentrasi kaporit yang didapat tersebut, kemudian dikonversi ke dalam bentuk gas dan hasil yang didapat sebesar $0,19 \mathrm{~kg} / \mathrm{jam}$. Hasil tersebut menunjukkan bahwa injeksi yang sudah diberikan dilapangan sebesar $0,5 \mathrm{~kg} / \mathrm{jam}$, telah sesuai dengan batas minimum dan air hasil olahan dapat disimpulkan sesuai dengan standar kualitas air minum, dengan parameter sisa khlor.

\section{UCAPAN TERIMA KASIH}

Ucapan terimakasih penulis tujukan kepada segenap pihak dari PDAM Kabupaten Lamongan, Segenap pihak di Kabupaten Lamongan dan Jurusan Teknik Lingkungan FTSP ITS, atas bantuan dan dukungan dalam penyelesaian perencanaan ini.

\section{DAFTAR PUSTAKA}

[1] Rivai, Y. 2006. Evaluasi Sistem Distribusi dan Rencana Peningkatan Pelayanan Air Bersih PDAM Kota Gorontalo. Jurnal SMARTek, 4, 2:126 - 134 .

[2] Hassan, F. 2014. Pemodelan Penurunan Sisa Chlor Jaringan Distribusi Air Minum dengan Epanet (Studi Kasus Kecamatan Sukun Kota Malang). Jurnal Teknik POMITS 3, 2: ISSN 2337 - 3539.

[3] Pemerintah Kabupaten Lamongan. 2014. Penyusunan Rencana Induk Sistem Penyediaan Air Minum Kabupaten Lamongan. Lamongan: Dinas Pekerjaan Umum Cipta Karya 